\title{
Monohydroxylated metabolites of the K2 synthetic cannabinoid JWH-073 retain intermediate to high cannabinoid 1 receptor (CB1R) affinity and exhibit neutral antagonist to partial agonist activity
}

\author{
Lisa K. Brents ${ }^{a}$, Anna Gallus-Zawada ${ }^{b}$, Anna Radominska-Pandya ${ }^{b}$, Tamara Vasiljevik ${ }^{c}$, \\ Thomas E. Prisinzano ${ }^{c}$, William E. Fantegrossi ${ }^{a}$, Jeffery H. Moran ${ }^{a, d}$, and Paul L. Prather ${ }^{a}{ }^{*}$ \\ aDepartment of Pharmacology and Toxicology, University of Arkansas for Medical Sciences, Little \\ Rock, AR, 72205, USA \\ ${ }^{b}$ Department of Biochemistry and Molecular Biology, University of Arkansas for Medical Sciences, \\ Little Rock, AR, 72205, USA \\ 'Department of Medicinal Chemistry, The University of Kansas, Lawrence, KS, 66045-7582, USA \\ dPublic Health Laboratory, Arkansas Department of Health, Little Rock, AR, 72205, USA
}

\section{Abstract}

K2 and several similar purported "incense products" spiked with synthetic cannabinoids are abused as cannabis substitutes. We hypothesized that metabolism of JWH-073, a prevalent cannabinoid found in $\mathrm{K} 2$, contributes to toxicity associated with $\mathrm{K} 2$ use. Competition receptor binding studies and G-protein activation assays, both performed by employing mouse brain homogenates, were used to determine the affinity and intrinsic activity, respectively, of potential monohydroxylated (M1, M3-M5) and monocarboxylated (M6) metabolites at cannabinoid 1 receptors (CB1Rs). Surprisingly, M1, M4 and M5 retain nanomolar affinity for CB1Rs, while M3 displays micromolar affinity and M6 does not bind to CB1Rs. JWH-073 displays equivalent efficacy to that of the CB1R full agonist CP-55,940, while M1, M3, and M5 act as CB1R partial agonists, and M4 shows little or no intrinsic activity. Further in vitro investigation by Schild analysis revealed that $\mathrm{M} 4$ acts as a competitive neutral CB1R antagonist $\left(\mathrm{K}_{\mathrm{b}} \sim 40 \mathrm{nM}\right)$. In agreement with in vitro studies, M4 also demonstrates CB1R antagonism in vivo by blunting cannabinoid-induced hypothermia in mice. Interestingly, M4 does not block agonist-mediated responses of other measures in the cannabinoid tetrad (e.g., locomotor suppression, catalepsy or analgesia). Finally, also as predicted by in vitro results, M1 exhibits agonist activity in vivo by inducing significant hypothermia and suppression of locomotor activity in mice.

In conclusion, the present study indicates that further work examining the physiological effects of synthetic cannabinoid metabolism is warranted. Such a complex mix of metabolically produced CB1R ligands may contribute to the adverse effect profile of JWH-073-containing products.

(C) 2012 Elsevier Inc. All rights reserved.

*Corresponding author. Tel.:+1 501686 5512; fax: +1 501686 5521. PratherPaulL @uams.edu.

Publisher's Disclaimer: This is a PDF file of an unedited manuscript that has been accepted for publication. As a service to our customers we are providing this early version of the manuscript. The manuscript will undergo copyediting, typesetting, and review of the resulting proof before it is published in its final citable form. Please note that during the production process errors may be discovered which could affect the content, and all legal disclaimers that apply to the journal pertain. 


\section{Keywords}

K2/Spice; JWH-073; CB1; cannabinoid; synthetic cannabis; obesity

\section{Introduction}

K2, Spice and a variety of similar "incense products" (hereafter referred to collectively as "K2") are currently emerging drugs of abuse with psychotropic effects mimicking those of marijuana [1-3]. K2 is made by adulterating plant matter with any of several diverse mixtures of synthetic cannabinoids, which are molecules that act in the brain similarly to $\Delta^{9}$-tetrahydrocannabinol $(\Delta-\mathrm{THC})$, the major psychoactive molecule present in marijuana. Many of the most prevalent of these synthetic cannabinoids are structurally distinct relative to $\Delta$-THC (Figures $1 \mathrm{~A}$ and $\mathrm{B}$ ) and individual $\mathrm{K} 2$ products are often quite variable in composition and unpredictable in content. For example, one study details the analytical detection of 11 different synthetic cannabinoids across 40 batches of 16 different incense products in various combinations and proportions from brand to brand and from batch to batch, even within brands [4]. Many K2 components were previously unregulated by legislative authorities in the U.S., and K2 use is undetectable by standard drug urine tests. Reportedly, these properties contribute to the motivation for $\mathrm{K} 2$ use by individuals seeking to attain the mood-altering effects of cannabis, while evading detection, prosecution and potential incarceration [5]. Compared to marijuana, K2 use is associated with an apparently higher prevalence of severe adverse effects, such as hypertension, tachycardia, hallucinations, agitation, seizures and panic attacks that often require immediate medical care [6-12]. The American Association of Poison Control Centers (AAPCC) reported handling 2,874 calls in the year 2010 regarding toxicities experienced by individuals after using K2 [13]. Data and reports such as these prompted the United States Drug Enforcement Administration (USDEA) to temporarily classify five common K2 synthetic cannabinoids (JWH-018, JWH-073, JWH-200, CP-47,497, and cannabicyclohexanol) as Schedule I substances on March 1, 2011, until greater understanding regarding the health consequences of their use can be established [14]. Despite this ban, as of November 30, 2011, a reported 6,348 calls regarding K2 use have been made to the AAPCC in 2011 alone [15], which is more than double the 2010 report, indicating an apparent persistence of $\mathrm{K} 2$ use that results in adverse effects $[5,16]$. All of these data are particularly alarming given the recent finding that one in nine high school seniors admitted to using K2 over the past year, making K2 the second most frequently used illicit drug, after marijuana, among high school seniors [17]

Synthetic cannabinoids found in $\mathrm{K} 2$, as well as $\Delta^{9}$-THC and other cannabinoids, induce psychotropic effects by binding and activating cannabinoid 1 receptors (CB1Rs) in the CNS $[18,19]$. CB1Rs are G-protein coupled receptors (GPCRs) found in highest abundance in the brain, and in lesser amounts in the liver [20], muscle and adipose tissues [21], gastrointestinal tract [22], bone [23], and reproductive system [24]. Most scientific data available regarding $\mathrm{K} 2$ to date has focused on determining product composition [4, 25], detecting useful biomarkers for compound detection in urine and serum [26-28], and reporting commonly observed adverse clinical effects $[10,11]$. However, there is a general lack of knowledge concerning K2 metabolism, pharmacology and toxicology.

One synthetic cannabinoid often present in K2 is JWH-073 [25, 29, 30]. JWH-073 is a member of the JWH aminoalkylindole family, which was originally synthesized to study the endocannabinoid system [31]. "Co-abuse" of JWH-073 with JWH-018 (a commonly abused CB1R full agonist that is structurally similar to JWH-073) has been anecdotally reported to reduce JWH-018-induced anxiety, resulting in a more "mellow", cannabis-like high compared to use of JWH-018 alone [32]. 
Although little is known concerning the biotransformation of the synthetic cannabinoids present in K2, initial studies have demonstrated that several Phase I monohydroxylated and carboxylated metabolites of both JWH-018 and JWH-073 are the major metabolites excreted in the urine of K2 users [26-28, 33, 34]. Recently, our laboratory reported that several monohydroxylated JWH-018 metabolites unexpectedly retain high affinity and intrinsic activity at CB1Rs [35], leading us to suggest that these and/or additional active metabolites likely contribute to the mechanism of K2 toxicity. Here, we hypothesize that biotransformation of JWH-073 produces similar metabolites (Figure 1) possessing high affinity and/or activity at CB1Rs, resulting in complex interactions with other synthetic cannabinoids and their metabolites present in K2. The combined action of all active synthetic cannabinoids formed likely produces an "entourage effect" that contributes to the increased incidence of severe adverse effects observed with $\mathrm{K} 2$ relative to marijuana use. Therefore, we first examined the in vitro affinity and activity of one carboxylated and four monohydroxylated derivatives of JWH-073 at CB1Rs. These initial findings led us to further characterize the in vitro and in vivo pharmacology of two molecules, M1 and M4, for potential actions as a CB1R agonist and antagonist, respectively.

\section{Methods}

\subsection{Materials}

All compounds were stored at $-20^{\circ} \mathrm{C}$, thawed and diluted in vehicle for use in subsequent experiments. JWH-073, M1, M3-M6 (Figure 1) were purchased from Cayman Chemical (Ann Arbor, MI), and diluted to a stock solution with a final concentration of either $10^{-2} \mathrm{M}$ (for $\left[{ }^{35} \mathrm{~S}\right] \mathrm{GTP} \gamma \mathrm{S}$ binding assays) or $10^{-3} \mathrm{M}$ (for competition receptor binding) in $100 \%$ ethanol. JWH-018 was synthesized as previously described [36-38] and validated by $\left[{ }^{1} \mathrm{H}\right]$ Nuclear Magnetic Resonance (NMR), $\left[{ }^{13} \mathrm{C}\right] \mathrm{NMR}$, Distortionless Enhancement by Polarization Transfer (DEPT)-135, Heteronuclear Single Quantum Correlation (HSQC) spectrometry, and mass spectrometry (MS). JWH-018 was diluted to a stock solution of $10^{-2} \mathrm{M}$ with $100 \%$ ethanol. $\Delta^{9}$-THC was supplied by the National Institute on Drug Abuse (NIDA, Bethesda, MD). WIN-55,212-2, CP-55,940, AM251, and O-2050 were purchased from Tocris Bioscience (Ellisville, MO), and SR141716 (Rimonabant) was purchased from Cayman Chemical. AM251, O-2050, and Rimonabant were diluted to $10^{-2} \mathrm{M}$ with dimethyl sulfoxide (DMSO), while $\Delta^{9}$-THC and CP-55,940 were diluted to $10^{-2} \mathrm{M}$ and WIN-55, $212-2$ to $10^{-3} \mathrm{M}$ in $100 \%$ ethanol. GTP $\gamma \mathrm{S}$ and GDP used in the $\left[{ }^{35} \mathrm{~S}\right] \mathrm{GTP} \gamma \mathrm{S}$ assay were purchased from EMD Chemical (Gibbstown, NJ) and Sigma Aldrich (St. Louis, MO), respectively, and dissolved in water to a stock concentration of $10^{-2} \mathrm{M}$. Adenosine deaminase from bovine spleen (Type IX, ammonium sulfate suspension) was purchased from Sigma Aldrich (St. Louis, MO), and diluted in $20 \mathrm{mM}$ HEPES buffer to 100 units $/ \mathrm{mL}$. $\left[{ }^{3} \mathrm{H}\right] \mathrm{CP}-55,940(144.0 \mathrm{Ci} / \mathrm{mmol})$ was purchased from Perkin Elmer (Waltham, MA) and $\left.{ }^{35} \mathrm{~S}\right] \mathrm{GTP} \gamma \mathrm{S}$ (1250 Ci/mmol) was purchased from American Radiolabeled Chemicals (St. Louis, MO). For all in vivo studies, cannabinoids were dissolved and administered in a vehicle consisting of a 1:1:18 ratio of absolute ethanol:emulphor:physiological saline, and injected in a volume equal to $10 \mathrm{~mL} / \mathrm{kg}$.

\subsection{Membrane Preparation}

Mouse brain homogenates for in vitro assays were prepared as previously described [39]. Briefly, whole brains were harvested from B6SJL mice, snap-frozen in liquid nitrogen and stored at $-80^{\circ} \mathrm{C}$. On the day membrane homogenates were to be prepared, brains were thawed on ice, then pooled in a $40 \mathrm{~mL}$ Dounce glass homogenizer and suspended in 5 volumes of ice cold homogenization buffer (50 mM HEPES, pH 7.4, $3 \mathrm{mM} \mathrm{MgCl}_{2}$, and 1 mM EGTA). Brains were then subjected to 10 complete strokes with an A pestle, followed by centrifugation at $40,000 \times g$ for 10 minutes at $+4^{\circ} \mathrm{C}$. Resulting supernatants were 
discarded, and the pellet was resuspended, homogenized and centrifuged similarly twice more, with supernatants being discarded. For the final resuspension and homogenization with a B pestle, ice-cold $50 \mathrm{mM}$ HEPES was used in place of homogenization buffer, and homogenates were aliquoted and stored at $-80^{\circ} \mathrm{C}$. Protein concentrations of homogenates were determined using the $\mathrm{BCA}^{\mathrm{TM}}$ Protein Assay (Thermo Scientific, Rockford, IL).

\subsection{Competition Receptor Binding Assay}

Competition receptor binding was performed as previously described [40]. Briefly, $50 \mu \mathrm{g}$ of mouse brain homogenates were incubated for 90 minutes to attain equilibrium binding at room temperature with $0.2 \mathrm{nM}\left[{ }^{3} \mathrm{H}\right] \mathrm{CP}-55,940,5 \mathrm{mM} \mathrm{MgCl}_{2}$, and either increasing cannabinoid concentrations $(0.1 \mathrm{nM}$ to $10 \mu \mathrm{M}), 10 \mu \mathrm{M}$ WIN-55,212-2 (for non-specific binding) or vehicle (for total binding), in triplicate, in a volume of $1 \mathrm{~mL}$ of buffer containing $50 \mathrm{mM}$ Tris, $0.05 \%$ bovine serum albumin (BSA) and $1 \%$ ethanol vehicle. Reactions were terminated by rapid vacuum filtration through Whatman GF/B glass fiber filters, followed by five washes with ice-cold buffer ( $50 \mathrm{mM}$ Tris, $0.05 \% \mathrm{BSA})$. Filters were immediately placed into $7 \mathrm{~mL}$ scintillation vials to which $4 \mathrm{~mL}$ of ScintiVerse ${ }^{\mathrm{TM}}$ BD Cocktail scintillation fluid (Fisher Scientific, Fair Lawn, NJ) was added. Bound radioactivity was determined after overnight incubation at room temperature and shaking, by liquid scintillation spectrophotometry with an efficiency of 44\% (Tri Carb 2100 TR Liquid Scintillation Analyzer, Packard Instrument Company, Meriden, CT). Specific binding is expressed as total binding minus non-specific binding, and is graphed for each data point as a percentage of specific binding occurring in the absence of any competitor.

\section{4. $\left[{ }^{35} \mathrm{~S}\right] \mathrm{GTPYS}$ Binding Assay}

$\left[{ }^{35} \mathrm{~S}\right] \mathrm{GTP} \gamma \mathrm{S}$ binding was performed as previously described [35]. Briefly, $25 \mu \mathrm{g}$ of mouse brain homogenates were incubated for 30 minutes at $30^{\circ} \mathrm{C}$ with $0.1 \mathrm{nM}\left[{ }^{35} \mathrm{~S}\right] \mathrm{GTP} \gamma \mathrm{S}, 10 \mu \mathrm{M}$ GDP, and either cannabinoid +/- antagonist, $10 \mu \mathrm{M}$ unlabeled GTP $\gamma \mathrm{S}$ (non-specific binding) or vehicle (total binding), in triplicate, in a volume of $1 \mathrm{~mL}$ of buffer containing 20 $\mathrm{mM}$ HEPES, $10 \mathrm{mM} \mathrm{MgCl} 2,100 \mathrm{mM} \mathrm{NaCl}, 20$ units/L adenosine deaminase, $0.05 \% \mathrm{BSA}$ and the appropriate DMSO $(0.1 \%)$ and/or ethanol ( $₫ 5.2 \%$ ) vehicle. Assay buffer containing $100 \mathrm{mM} \mathrm{KCl}$, instead of $100 \mathrm{mM} \mathrm{NaCl}$, was used to increase basal G-protein activity in experiments examining inverse agonism. Reactions were terminated by quick vacuum filtration through Whatman GF/B glass fiber filters, followed by five washes with ice-cold buffer (20 mM HEPES, $0.05 \%$ BSA). Filters were immediately placed into $7 \mathrm{~mL}$ scintillation vials to which $4 \mathrm{~mL}$ of ScintiVerse ${ }^{\mathrm{TM}}$ BD Cocktail scintillation fluid was added. Bound radioactivity was determined after overnight incubation at room temperature and shaking by liquid scintillation spectrophotometry with an efficiency of 93\% (Tri Carb 2100 TR Liquid Scintillation Analyzer, Packard Instrument Company, Meriden, CT). Specific binding is expressed as picomoles of $\left[{ }^{35} \mathrm{~S}\right] \mathrm{GTP} \gamma \mathrm{S}$ bound per $\mathrm{mg}$ of protein.

\subsection{Animal Care and Use}

All studies were carried out in accordance with the Declaration of Helsinki and with the Guide for Care and Use of Laboratory Animals as adopted and promulgated by the National Institutes of Health. Experimental protocols were approved by the Animal Care and Use Committee at the University of Arkansas for Medical Sciences (Animal Use Protocol \#3155).

Prior to surgery (see below), male NIH Swiss mice (Harlan Sprague Dawley Inc., Indianapolis, IN), weighing approximately $25-30 \mathrm{~g}$, were housed 3 animals per Plexiglas ${ }^{\circledR}$ cage $(15.24 \times 25.40 \times 12.70 \mathrm{~cm})$ in a temperature-controlled room in an Association for Assessment and Accreditation of Laboratory Animal Care (AAALAC) accredited animal facility at the University of Arkansas for Medical Sciences. Room conditions were 
maintained at $22 \pm 2{ }^{\circ} \mathrm{C}$ and $45-50 \%$ humidity. Lights were set to a 12-h light/dark cycle. Animals were fed Lab Diet rodent chow (Laboratory Rodent Diet \#5001, PMI Feeds, Inc., St. Louis, MO) and water ad libitum throughout testing. Animals were acclimated to the laboratory environment for $\sim 7$ days prior to experiments, and to the biotelemetry chambers for at least 2 hours prior to initiation of data acquisition. All test conditions used groups of 5 or 6 mice, and all mice were drug-naïve (with the exception of surgical anesthetics) prior to testing.

\subsection{Cannabinoid Tetrad}

Cannabinoid effects on core temperature and locomotor activity were measured using surgically-implanted biotelemetry probes. Following appropriate anesthetization with ketamine $(100 \mathrm{mg} / \mathrm{kg}$, intraperitoneal [i.p.]) and xylazine $(10 \mathrm{mg} / \mathrm{kg}$, i.p.), the abdominal area of each mouse was shaved and sanitized with iodine swabs. A rostral-caudal cut approximately $1.5 \mathrm{~cm}$ in length was made with skin scissors, providing access to the intraperitoneal cavity. A cylindrical glass-encapsulated radiotelemetry probe (model ER-4000 E-Mitter, Mini Mitter Co., Inc., Bend, OR) was then inserted, and the incision was closed using absorbable 5-0 chromic gut suture material. At least 7 days were imposed between surgery and experimental observation of cannabinoid effects to allow incisions to heal and mice to recover normal body weights. Following surgery, implanted mice were individually housed in Plexiglas ${ }^{\circledR}$ mouse cages $(15.24 \times 25.40 \times 12.70 \mathrm{~cm})$ for the duration of all temperature and locomotor activity experiments. Implanted transmitters produced activity- and temperature-modulated signals that were transmitted to a receiver (model ER-4000 Receiver, Mini Mitter Co., Inc., Bend, OR) underneath each mouse cage. Receivers were housed in light- and sound-attenuating cubicles (Med Associates model ENV-022MD, St. Albans, VT) equipped with exhaust fans, which further masked ambient laboratory noise. On experimental days, mice were weighed, marked, and returned to their individual cages during which at least $1 \mathrm{hr}$ of baseline data were collected. Cannabinoid doses were then calculated and prepared for injection. Animals were subsequently removed from their cage and administered an intraperitoneal (i.p.,) injection with the indicated doses of JWH-018, JWH-073, M1, M4, JWH-018 plus M4, or an equivalent volume of vehicle. Mice were then placed into a new cage with fresh bedding to stimulate exploratory behavior. Temperature and locomotor activity data were collected at regular 5-min intervals and processed simultaneously by the Vital View data acquisition system (Mini Mitter Co., Inc., Bend, OR) for at least $10 \mathrm{hrs}$.

Analgesia was measured as tail-flick latency using the EMDIE-TF6 radiant heat apparatus (Emdie Instrument Co., Montpelier, VA). For each trial, mice were positioned on the stage of apparatus, while the tail was extended into a groove to break a photobeam. Beginning at $\mathrm{t}=0$, a button was depressed to begin a timer and illuminate a radiant heat source directed onto the dorsal surface of the tail, approximately $2 \mathrm{~cm}$ from its origin from the body. Movement of the tail at any point after the beginning of the trial broke the photobeam, stopped both the heat source and the timer, and ended the trial. One trial per mouse per time point was performed. Sensitivity and light intensity were set at 150 and 369, respectively (calibrated to produce a tail flick latency between 2 and 4 seconds for untreated mice), and maximum time for each trial was 10 seconds. Tail-flick latency was measured at $0,10,30$, and 60 minutes after either cannabinoid or vehicle administration.

Catalepsy was measured by the horizontal bar test, which utilized a cylindrical steel bar ( 0.5 $\mathrm{cm}$ in diameter) that was suspended $4.0 \mathrm{~cm}$ above and horizontal to a Plexiglas platform. To begin the test trial, a mouse was positioned with its forelimbs on the horizontal bar and its hindlimbs on the platform, in such a way that the mouse assumed a rearing posture. Upon placement on the catalepsy bar, a timer was started, and counted until the mouse removed both of its paws from the bar and assumed a non-rearing posture. A single trial per mouse 
per time point was performed, and the maximum time allowed on the bar was 30 seconds. Catalepsy scores were measured at $0,10,30$ and 60 minutes after administration of vehicle or cannabinoid.

\subsection{Statistical Analysis}

Curve fitting and statistical analyses for in vitro experiments were performed using GraphPad Prism version 5.0b (GraphPad Software Inc., San Diego, CA). The Cheng-Prusoff equation [41] was used to convert the experimental $\mathrm{IC}_{50}$ values obtained from competition receptor binding experiments to $\mathrm{K}_{\mathrm{i}}$ values, a quantitative measure of receptor affinity. Nonlinear regression for one-site competition was used to determine the $\mathrm{IC}_{50}$ for competition receptor binding. Curve fitting of concentration-effect curves via non-linear regression was also employed to determine the $\mathrm{EC}_{50}$ (a measure of potency) and $\mathrm{E}_{\max }$ (a measure of efficacy) for $\left[{ }^{35} \mathrm{~S}\right] \mathrm{GTP} \gamma \mathrm{S}$ concentration-effects experiments. A power equation based on the Cheng-Prusoff equation was used to determine the $\mathrm{K}_{\mathrm{b}}$ of $\mathrm{M} 4$ from its $\mathrm{IC}_{50}$ to inhibit an $\mathrm{EC}_{90}$ concentration of CP-55,940 [42]. Schild analysis as previously described by Thomas, et. al. [43] was also performed to determine $K_{b}$ and Schild slope for the ability of M4 to shift the JWH-018 concentration effect curves for G-protein activation. Data are expressed as mean \pm SEM. The Student's $t$-test was used to determine statistical significance $(\mathrm{P}<0.05)$ between two groups, while a one-way ANOVA, followed by Tukey's Multiple Comparison post-hoc test, was used to determine statistical significance $(\mathrm{P}<0.05)$ between three or more groups.

For core body temperature experiments, the area under the curve (AUC) was calculated using a trapezoidal rule from $0-500$ minutes, and statistical significance $(\mathrm{P}<0.05)$ was determined using a one-way ANOVA, followed by Tukey's HSD post-hoc test. For locomotor activity, total locomotor counts were summed from 0-800 minutes. Because locomotor, analgesia and catalepsy data were not normally distributed, Kruskal-Wallis oneway ANOVA on ranks were performed, and all pair-wise comparisons were then made using the Tukey's HSD tests. In vivo statistical calculations were performed using SigmaStat 3 (Systat Software, Inc., San Jose, CA).

\section{Results}

\subsection{JWH-073, M1, M4, and M5 bind to CB1Rs with intermediate to high affinity}

Saturation binding experiments using the radiolabeled, high-affinity cannabinoid agonist $\left[{ }^{3} \mathrm{H}\right] \mathrm{CP}-55,940$ determined that mouse brain homogenates employed for these experiments contain a CB1R density of $2.44 \pm 0.15 \mathrm{pmol} / \mathrm{mg}$ protein, to which $\left[{ }^{3} \mathrm{H}\right] \mathrm{CP}-55,940$ binds with a $K_{d}$ of $0.37 \pm 0.07 \mathrm{nM}(\mathrm{n}=3)$. To determine the affinity $\left(\mathrm{K}_{\mathrm{i}}\right)$ of JWH-073, M1, and M3-M6 (Figure 1) for CB1Rs, initial competition receptor binding studies with $\left[{ }^{3} \mathrm{H}\right] \mathrm{CP}-55,940$ were conducted (Figure 2, Table 1). Specifically, the ability of increasing concentrations of each compound to displace $\left[{ }^{3} \mathrm{H}\right] \mathrm{CP}-55,940$ from CB1Rs present in mouse brain homogenates was examined. In agreement with previous reports [44], JWH-073 bound to CB1Rs with high affinity $(12.9 \pm 3.4 \mathrm{nM}, \mathrm{n}=6$, Table 1$)$. Interestingly, M1 also displayed remarkably high affinity for CB1Rs, equivalent to that of the parent compound $(14.1 \pm 3.5 \mathrm{nM}, \mathrm{n}=3)$. The affinities of M4 and M5 for CB1Rs were slightly lower, but still in the intermediate nanomolar range (122.2 $\pm 16.2 \mathrm{nM}$ and $224.2 \pm 9.0 \mathrm{nM}$, respectively, $\mathrm{n}=3-4)$, predicting that even if relatively low concentrations of these compounds are formed via metabolism, they likely produce physiologically relevant effects via binding and modulation of CB1R activity in vivo. M3 bound to CB1Rs with a low micromolar affinity $(1.28 \pm 0.47 \mu \mathrm{M}, \mathrm{n}=4)$, while concentrations of $\mathrm{M} 6$ as high as $10 \mu \mathrm{M}$ produced less than $10 \%$ displacement of $\left[{ }^{3} \mathrm{H}\right] \mathrm{CP}-55,940$ specific binding $(\mathrm{n}=3)$, signifying little or no CB1R affinity. 
3.2. M1, M3 and M5 act as CB1R partial agonists with equivalent efficacy to stimulate Gprotein activity, while M4 lacks intrinsic activity

The intrinsic activity of JWH-073, M1, and M3-M6 at CB1Rs was next determined by employing the $\left[{ }^{35} \mathrm{~S}\right] \mathrm{GTP} \gamma \mathrm{S}$ binding assay, which measures G-protein activation, in mouse brain homogenates. Initially, the G-protein activation induced by a receptor-saturating concentration $(10 \mu \mathrm{M})$ of each compound was examined (Figure 3A, Table 2). JWH-073 displayed equivalent efficacy relative to the full CB1R agonist, CP-55,940 (0.28 \pm 0.03 vs. $0.32 \pm 0.02$ pmole $/ \mathrm{mg}$, respectively, $\mathrm{n}=3-5)$. M1, M3 and M5 surprisingly retained partial agonist activity $(0.14 \pm 0.01,0.11 \pm 0.02$, and $0.16 \pm 0.02 \mathrm{pmole} / \mathrm{mg}$, respectively, $\mathrm{n}=3-4)$, producing greater than or equivalent activation of G-proteins relative to that produced by $\Delta^{9}$-THC $(0.08 \pm 0.00 \mathrm{pmole} / \mathrm{mg})$. In contrast, M4 and M6 produced negligible G-protein activation in mouse brain homogenates. Interestingly, $10 \mu \mathrm{M}$ THC (Figure 3A) produces less G-protein activation than a $1 \mu \mathrm{M}$ concentration (Figure 3B). These data parallel our observations that in this assay, under these experimental conditions, THC consistently exhibits a bi-phasic concentration-effect curve with concentrations greater than $1 \mu \mathrm{M}$ producing less activation than lower concentrations examined (see Figure 4).

To confirm that CP-55,940, JWH-073, M1, M3 and M5 produced G-protein activation via specific interaction with CB1Rs, the effect of co-administration with a CB1R-selective neutral antagonist $\mathrm{O}-2050(1 \mu \mathrm{M})$ to attenuate $\mathrm{EC}_{90}$ concentrations $(1 \mu \mathrm{M}$ for all compounds except CP-55,940, which instead was $100 \mathrm{nM}$ ) of the cannabinoids was examined (Figure 3B, Table 2). The increase in $\left[{ }^{35} \mathrm{~S}\right] \mathrm{GTP} \gamma \mathrm{S}$ binding produced by each of these agonists was significantly reduced by $\mathrm{O}-2050$, indicating that these compounds all activated G-proteins in mouse brain homogenates by a CB1R-dependent mechanism.

Concentration-effect studies were conducted to determine a measure of potency (e.g., $\mathrm{EC}_{50}$ ) for G-protein activation by $\mathrm{M} 1$ and to further validate a receptor-mediated mechanism for the intrinsic activity reported (Figure 4, Table 1). As anticipated, G-protein activation produced by CP-55,940, JWH-073, $\Delta^{9}-$ THC and M1 was concentration-dependent, with maximal efficacies (e.g., $\mathrm{E}_{\max }$ values) that agree well with data presented in Figure 3A. Collectively, these data indicate that CP-55,940 and JWH-073 act as full CB1R agonists, while M1, M3 and M5 exhibit partial agonist activity, and M4 lacks significant intrinsic activity at CB1Rs.

\subsection{M4 acts as an in vitro competitive neutral antagonist at CB1Rs with nanomolar potency $\left(\mathrm{K}_{\mathrm{b}}\right)$}

Although M4 bound with intermediate nanomolar affinity to CB1Rs (e.g., $122 \mathrm{nM}$; Figure 2 ), it neither significantly activated nor inhibited basal G-protein activity and thus was devoid of intrinsic activity as measured by this functional assay (Figure 3). These combined observations intriguingly predict that M4 might serve as a physiologically relevant neutral antagonist at CB1Rs; hence it was selected for further characterization. First, concentrations of M4 alone ranging from $0.1 \mathrm{nM}$ to $10 \mu \mathrm{M}$ neither significantly increased (characteristic of agonists), nor decreased (characteristic of inverse agonists), basal $\left[{ }^{35} \mathrm{~S}\right] \mathrm{GTP} \gamma \mathrm{S}$ binding levels (Figure 5A). These observations indicate that M4 may act as a neutral CB1R antagonist concerning G-protein regulation in mouse brain homogenates. Second, the ability of co-administration with a receptor saturating concentration of M4 $(10 \mu \mathrm{M})$ to antagonize effects on G-protein activity produced by three different CB1R agonists (Figure 5B) or two CB1R inverse agonists (Figure 5C) was examined. In all cases, co-incubation with M4 significantly antagonized the action of agonists (to increase) or inverse agonists (to reduce) $\left.{ }^{35} \mathrm{~S}\right] \mathrm{GTP} \gamma \mathrm{S}$ binding. Third, a measure of the potency of CB1R antagonism produced by M4 was investigated by determining the antagonist dissociation constant (e.g., $\mathrm{K}_{\mathrm{b}}$ ) at CB1Rs, for two different agonists employing two alternative but complementary methods (Figure 6). 
Initially, the ability of increasing concentrations of $\mathrm{M} 4$ to reduce $\left[{ }^{35} \mathrm{~S}\right] \mathrm{GTP} \gamma \mathrm{S}$ binding induced by a single $\mathrm{EC}_{90}$ concentration of CP-55,940 (100 nM) in mouse brain homogenates was conducted (Figure 6A). Co-incubation with M4 produced a concentration-dependent decrease in CP-55,940-induced $\left.{ }^{35} \mathrm{~S}\right] \mathrm{GTP} \gamma \mathrm{S}$ binding. Conversion of the $\mathrm{IC}_{50}$ of this curve to a measure of antagonist potency by employing a modified function of the Cheng-Prusoff equation [42], revealed a $\mathrm{K}_{\mathrm{b}}$ value $40.3 \mathrm{nM}$ for M4. Schild analysis [43] was additionally conducted to determine not only the $\mathrm{K}_{\mathrm{b}}$ value of M4, but also whether M4 produces competitive or non-competitive antagonism at CB1Rs (Figure 6B). Since JWH-073 and JWH-018 are often co-abused, as noted by their concurrent presence in $\mathrm{K} 2$ products, as well as accounts of users combining JWH-018 with JWH-073 in deliberate ratios [32], we examined the ability of M4 to antagonize the G-protein activation produced by JWH-018. The ability of three different M4 concentrations $(1,3$, and $10 \mu \mathrm{M})$ to shift the $\left[{ }^{35} \mathrm{~S}\right] \mathrm{GTP} \gamma \mathrm{S}$ binding curve produced by JWH-018 was investigated (Figure 6B). M4 produced a concentration-dependent shift-to-the-right of the JWH-018 curve without affecting maximal efficacy. Specifically, JWH-018 alone activates G-proteins with an $\mathrm{EC}_{50}$ of $8 \mathrm{nM}$, which is in close agreement with data previously published [35]. However, in the presence of increasing concentrations of M4, the $\mathrm{EC}_{50}$ of JWH-018 increased to 178,263 , and $1562 \mathrm{nM}$. This yielded a Schild plot with a slope of 0.97 (Figure 6B, inset) and a $\mathrm{K}_{\mathrm{b}}$ of $48.1 \mathrm{nM}$. This value is in close agreement with the $\mathrm{K}_{\mathrm{b}}$ determined in Figure 6A (e.g., $\left.40.3 \mathrm{nM}\right)$ and, most importantly, clearly indicates that M4 is a potent, competitive antagonist at CB1Rs.

\subsection{M1 displays JWH-073-like activity in vivo}

M1 was tested in NIH Swiss Mice for effects on two well-established cannabinoid endpoints, core body temperature and locomotor activity, as was similarly performed in our previous study examining JWH-018 and its M1 derivative [35]. As reported in that study, cannabinoids induce hypothermia and suppress locomotor activity [45]. In the present study, mice were implanted with telemetry probes that simultaneously measure core body temperature and locomotor activity as described previously in the "Methods" section. Administration of JWH-073 or M1 (10 mg/kg, i.p.) resulted in sharp drops in core body temperature, with the minimum temperatures recorded being $29.74 \pm 1.44^{\circ} \mathrm{C}$ for JWH-073 and $30.32 \pm 0.66^{\circ} \mathrm{C}$ for $\mathrm{M} 1$ (Figure 7A). Time to maximal core body temperature reduction $\left(\mathrm{T}_{\max }\right)$ did not differ for the two cannabinoids examined (54.17 \pm 5.23 minutes for the parent compound and $58.00 \pm 4.64$ minutes for M1), suggesting a similar pharmacokinetic profile. Simultaneously, M1 resulted in a reduction of locomotor activity similar to that observed with administration of JWH-073 (Figure 7B). Taken together, these data suggest that M1 retains a substantial portion of the in vivo activity exhibited by the parent compound.

\subsection{M4 antagonizes JWH-018-induced hypothermia in vivo}

The observation that M4 behaves as a neutral, competitive CB1R antagonist in vitro prompted the investigation of its potential CB1R antagonist activity in vivo. In the following experiments, M4 (10 mg/kg, i.p.) was co-administered in NIH Swiss mice with JWH-018 (3 $\mathrm{mg} / \mathrm{kg}$, i.p.) to determine if M4 antagonizes four different measures of in vivo cannabinoid activity, commonly known as the cannabinoid tetrad: hypothermia, locomotor activity suppression (both described in the previous subsection), analgesia, and catalepsy. Previous work in this model showed that JWH-018 (3 mg/kg, i.p.) significantly decreases core body temperature and locomotor activity [35]. Initially, a dose of $10 \mathrm{mg} / \mathrm{kg}$, i.p., of M4 was administered to test its antagonism of the hypothermic effects induced by JWH-018 (3 mg/ $\mathrm{kg}$, i.p.). This dose of M4 was chosen for initial in vivo experiments because of the striking cannabimimetic effects elicited by $10 \mathrm{mg} / \mathrm{kg}$, i.p. of the structurally similar M1 derivatives of both JWH-018 [35] and JWH-073 (see previous subsection). In the present study, $3 \mathrm{mg} /$ $\mathrm{kg}$ of JWH-018 administered i.p. produces hypothermia as indicated by a maximal decrease in core body temperature to $30.28+/-0.71{ }^{\circ} \mathrm{C}$ (Figure $8 \mathrm{~A}$ ). In marked contrast, M4 resulted 
in no significant change in body temperature. Significantly, hypothermia induced by JWH-018 was blunted by co-administration with M4 (to $33.09+/-0.70{ }^{\circ} \mathrm{C}$ ). Although coadministration with $\mathrm{M} 4$ did not completely prevent the reduction in body temperature produced by JWH-018, it did significantly blunt JWH-018-induced hypothermia (Figure 8B). Quantification of this effect is indicated by summation of area under the curve (AUC) data generated 0-500 minutes after injection. Most importantly, these data demonstrate that M4 acts as a CB1R antagonist not only in vitro, but also in vivo.

Potential antagonism of other JWH-018-induced effects (analgesia, catalepsy, and locomotor suppression) by this dose of M4 was also examined. Coadministration of M4 with JWH-018 ( $3 \mathrm{mg} / \mathrm{kg}$, i.p.,) showed no difference in these assays from JWH-018 alone (Figure 9). In all cases, the overall ANOVA was significant due to main effects of time ( $\mathrm{P}=0.002$ for locomotor activity. $\mathrm{P}=0.004$ for analgesia, and $\mathrm{P}=0.003$ for catalepsy), but there were no between-group comparisons at any time point that reached statistical significance.

\section{Discussion}

This study is the first to report that potential monohydroxylated metabolites of JWH-073 retain physiologically relevant, high (M1), intermediate (M4 and M5) and low (M3) affinity for CB1Rs. M1, M3, and M5 also activate G-proteins in a CB1R-dependent manner with partial agonist activity equivalent to that produced by the major psychoactive constituent in marijuana, $\Delta^{9}$-THC. M1 was further characterized for potential in vivo activity and, similar to JWH-073, induces hypothermia and suppresses locomotor activity in mice. M4 was also importantly shown to act as a novel competitive neutral CB1R antagonist. Specifically, $\left.{ }^{35} \mathrm{~S}\right]$ GTP $\gamma \mathrm{S}$ binding experiments demonstrate that co-incubation with M4 blocks modulation of CB1R activity by both agonists and inverse agonists, with no effect on basal G-protein activity when tested alone. M4 antagonizes CB1R-mediated G-protein activation by JWH-018 in a competitive manner with a $\mathrm{K}_{\mathrm{b}}$ value of $48 \mathrm{nM}$. Finally, M4 attenuates JWH-018-induced hypothermia in mice, while an equivalent dose does not antagonize other CB1R-dependent effects that are entirely mediated by CNS-specific CB1Rs. Both in vitro and in vivo data presented collectively indicate that metabolism of JWH-073 may produce a complex mix of metabolites exhibiting a range of CB1R intrinsic activity that work "in concert" to contribute to the biological actions of JWH-073-containing products. Furthermore, the neutral CB1R antagonist properties of M4 suggest that this molecule might serve as a scaffold for development of a novel class of anti-obesity drugs (discussed below).

The first novel finding reported here is that M1 and M5 retain high and intermediate affinity for CB1Rs, respectively. Furthermore, both compounds act in vitro as agonists at CB1Rs, while M1 was also shown to demonstrate $\mathrm{CB} 1 \mathrm{R}$ agonist activity in vivo. If future comprehensive pharmacokinetic studies confirm that metabolism of JWH-073 produces multiple active metabolites with significant CB1R affinity and activity (such as the ones examined in the present study), these acute actions could result in prolonged, excessive activation of CB1Rs. Furthermore, additive or synergistic actions exerted by multiple active metabolites, combined with the agonist activity of other synthetic cannabinoids present in $\mathrm{K} 2$ products, could potentially result in adverse effects rarely observed with marijuana, since $\Delta^{9}$-THC is metabolized to only one reported major active metabolite [46].

In addition to acute actions, sustained elevations of active cannabinoids following chronic K2 abuse would be expected to produce adaptive alterations in CB1R signaling [18, 47-49] that might interfere with normal endocannabinoid function. For example, prolonged endocannabinoid dysregulation could disrupt a wide variety of physiological functions including mood and cognition [50], appetite and energy homeostasis [51, 52], pain sensation [53], immune function [54], bone homeostasis [23] and reproduction [24]. In support of this 
suggestion, many similar adverse effects are observed following chronic cannabis use [5557].

It is also possible that prolonged exposure to $\mathrm{K} 2$ synthetic cannabinoids and their active metabolites may promote $\mathrm{K} 2$ dependence, characterized by a withdrawal syndrome upon abrupt cessation of use. Although the subject of cannabis dependence and withdrawal remains controversial, reliable evidence has accumulated to define a specific marijuana withdrawal syndrome in human subjects [58], occurring with a prevalence of approximately $9 \%$ in regular marijuana users [59]. Selective reduction in the density of cortical CB1Rs has also been reported in chronic cannabis users [60]. Such CB1R down-regulation would presumably result in reduced CB1R signaling, potentially contributing to the development of tolerance. It could therefore be predicted that chronic use of higher efficacy cannabinoids present in K2, coupled with the sustained action of associated active metabolites, might produce similar or even greater adaptations leading to enhanced levels of tolerance and/or dependence relative to chronic cannabis use.

If metabolism of JWH-073 results in accumulation of physiologically relevant concentrations of the CB1R antagonist M4 in the CNS, first-time exposure to JWH-073containing products may acutely precipitate withdrawal in high-intake cannabis and K2 users. In support of this hypothesis, it is interesting that symptoms of cannabis withdrawal resemble several adverse effects associated with K2 use (e.g., anxiety, aggression, irritability, hypertension) [61, 62]. High concentrations of M4 accumulating in the CNS could also promote compensatory escalations in $\mathrm{K} 2$ use in order to maintain the subjective, reinforcing effects of $\mathrm{K} 2$ use, while production of low or moderate concentrations of this antagonist may explain the "mellowness" attributed to JWH-073 relative to other synthetic cannabinoids [63]. In any case, both acute and chronic cellular responses resulting from use of JWH-073-containing products are possibly influenced by actions produced by a combination of the parent compound and its active metabolites.

Overactivity of the endocannabinoid system appears to contribute to development of obesity and metabolic syndrome [64]. As such, CB1R antagonists/inverse agonists showed great promise as anti-obesity agents. However, the first-in-class drug rimonabant was denied approval by the United States Food and Drug Administration (USFDA) and was subsequently removed from the European drug market due to severe psychiatric side effects, including depression, anxiety, and increased risk of suicide [65]. Although antagonism of endocannabinoids acting at CB1Rs in the CNS by rimonabant may cause these adverse reactions [66], recent evidence instead suggests that such psychiatric complications may be primarily associated with inverse agonist properties of these compounds that reduce the constitutive activity of CB1Rs in the CNS [67]. The majority of CB1R antagonists identified to date unfortunately possess inverse agonist activity [68]. However, recent studies in mice demonstrate that compounds acting as neutral CB1R antagonists (and not inverse agonists) also possess anti-obesity properties, but with reduced side effects relative to rimonabant [69, 70]. Therefore, the findings reported here that M4 is a neutral CB1R antagonist suggests that this molecule might serve as a scaffold for development of anti-obesity drugs that reduce an aberrantly high level of endocannabinoid signaling in obese individuals without altering constitutive CB1R activity, possibly resulting in fewer CNS effects.

CB1R antagonists with limited brain penetration also are efficacious anti-obesity agents with reduced adverse psychiatric effects [71]. Notably, M4 blunted, but did not completely block, CB1R-induced hypothermia (Figure 8). Furthermore, M4 curiously failed to antagonize other CB1R-mediated effects in the cannabinoid tetrad (Figure 9). These observations might be explained, in part, by a less than adequate dose of M4 selected for the in vivo antagonism studies. However, it is also tempting to speculate that M4 does not readily enter the brain to 
antagonize centrally mediated effects of JWH-018 (e.g., analgesia, catalepsy, and locomotor suppression), but can partially antagonize the effect of CB1R-induced hypothermia, which has been shown to be mediated, in part, by peripheral CB1Rs [72]. Further pharmacokinetic experiments will be required to validate the potential peripherally-restricted properties of M4 before definitive conclusions can be made.

Our group recently reported that several monohydroxylated metabolites of the synthetic cannabinoid JWH-018 retain high CB1R affinity and activity [35]. The current report similarly examined the affinity and activity of several potential JWH-073 metabolites at CB1Rs. Although the present study shows that potential monohydroxylated metabolites of JWH-073 also retain significant affinity and activity, a distinct difference between reports is discovery of M4: a neutral CB1R antagonist with nanomolar affinity and potential significance for development of anti-obesity therapeutics. Regardless of intrinsic activity, metabolites retaining high CB1R affinity have potential to exaggerate or disrupt cannabinoid signaling. The finding that multiple JWH-073 candidate metabolites retain high CB1R affinity and exhibit a range of intrinsic activity provides valuable mechanistic insight and suggests that biotransformation of K2 may contribute to the relatively high rate of severe adverse effects often reported with use of this rapidly emerging drug of abuse.

\section{Acknowledgments}

The work was supported by the Association of Public Health Laboratories Award (JHM), US PHS Grant RR020146 (WEF), UAMS Pilot Study Award (PLP) and a Pilot Research Award from the University of Arkansas for Medical Sciences Center for Clinical and Translational Research, supported by grant number 1UL1RR029884 from the National Center for Research Resources (JHM, WEF, and PLP). The funding agencies had no role in study design, data collection and analysis, decision to publish, or preparation of the manuscript.

\section{Abbreviations}

$\begin{array}{ll}\text { AAPCC } & \text { American Association of Poison Control Centers } \\ \text { BSA } & \text { bovine serum albumin } \\ \text { CB1 } & \text { cannabinoid 1 receptor } \\ \Delta^{9} \text {-THC } & \text { delta-9-tetrahydrocannabinol } \\ \text { GDP } & \text { guanosine diphosphate } \\ \text { GTP } \boldsymbol{\gamma} \text { S } & \text { guanosine } 5^{\prime} \text {-O-[gamma-thio]triphosphate } \\ \text { GPCR } & \text { G-protein coupled receptor } \\ \text { USDEA } & \text { United States Drug Enforcement Agency } \\ \text { USFDA } & \text { United States Food and Drug Administration }\end{array}$

\section{References}

1. Vardakou I, Pistos C, Spiliopoulou C. Spice drugs as a new trend: mode of action, identification and legislation. Toxicol Lett. 2010; 197:157-62. [PubMed: 20566335]

2. Auwarter V, Dresen S, Weinmann W, Muller M, Putz M, Ferreiros N. 'Spice' and other herbal blends: harmless incense or cannabinoid designer drugs? J Mass Spectrom. 2009; 44:832-7. [PubMed: 19189348]

3. Seely KA, Prather PL, James LP, Moran JH. Marijuana-based drugs: innovative therapeutics or designer drugs of abuse? Mol Interv. 2011; 11:36-51. [PubMed: 21441120]

4. Hudson S, Ramsey J, King L, Timbers S, Maynard S, Dargan PI, et al. Use of high-resolution accurate mass spectrometry to detect reported and previously unreported cannabinomimetics in "herbal high" products. J Anal Toxicol. 2010; 34:252-60. [PubMed: 20529459] 
5. Vandrey R, Dunn KE, Fry JA, Girling ER. A survey study to characterize use of Spice products (synthetic cannabinoids). Drug Alcohol Depend. 2011

6. Vearrier D, Osterhoudt KC. A teenager with agitation: higher than she should have climbed. Pediatr Emerg Care. 2010; 26:462-5. [PubMed: 20531137]

7. Muller H, Sperling W, Kohrmann M, Huttner HB, Kornhuber J, Maler JM. The synthetic cannabinoid Spice as a trigger for an acute exacerbation of cannabis induced recurrent psychotic episodes. Schizophr Res. 2010; 118:309-10. [PubMed: 20056392]

8. Muller H, Huttner HB, Kohrmann M, Wielopolski JE, Kornhuber J, Sperling W. Panic attack after spice abuse in a patient with ADHD. Pharmacopsychiatry. 2010; 43:152-3. [PubMed: 20127596]

9. Every-Palmer S. Synthetic cannabinoid JWH-018 and psychosis: An explorative study. Drug Alcohol Depend. 2011; 117:152-7. [PubMed: 21316162]

10. Young AC, Schwarz E, Medina G, Obafemi A, Feng SY, Kane C, et al. Cardiotoxicity associated with the synthetic cannabinoid, K9, with laboratory confirmation. Am J Emerg Med. 2011

11. Simmons J, Cookman L, Kang C, Skinner C. Three cases of "spice" exposure. Clin Toxicol (Phila). 2011; 49:431-3. [PubMed: 21740143]

12. Schneir AB, Cullen J, Ly BT. "Spice" girls: synthetic cannabinoid intoxication. J Emerg Med. 2011; 40:296-9. [PubMed: 21167669]

13. Wehrman, J. Fake Marijuana Spurs More than 4,500 Calls to US Poison Centers. American Association of Poison Control Centers; Alexandria, VA: 2011. <http://www.aapcc.org/dnn/ Portals/0/K2releasedec21.pdf>

14. Leonhart, MM. [Accessed 3 Jan 2011] Schedules of Controlled Substances: Temporary Placement of Five Synthetic Cannabinoids Into Schedule I; Federal Register. 2010. p. 71635-8.<http:// www.deadiversion.usdoj.gov/fed_regs/rules/2010/fr1124.htm>

15. AAPCC. [Accessed 17 Dec 2011] Synthetic Marijuana Data. 2011. <http://www.aapcc.org/dnn/ Portals/0/Synthetic\%20Marijuana\%20Data\%20for\%20Website\%2012.12.2011.pdf>

16. Hu X, Primack BA, Barnett TE, Cook RL. College students and use of K2: an emerging drug of abuse in young persons. Subst Abuse Treat Prev Policy. 2011; 6:16. [PubMed: 21745369]

17. Johnston, LD.; O’Malley, PM.; Bachman, JG.; Schulenberg, JE. Marijuana use continues to rise among US teens, while alcohol use hits historic lows. University of Michigan News Service; Ann Arbor, MI: 2011. 〈http://www.monitoringthefuture.org>

18. Atwood BK, Huffman J, Straiker A, Mackie K. JWH018, a common constituent of 'Spice' herbal blends, is a potent and efficacious cannabinoid CB receptor agonist. Br J Pharmacol. 2010; 160:585-93. [PubMed: 20100276]

19. Jarbe TU, Deng H, Vadivel SK, Makriyannis A. Cannabinergic aminoalkylindoles, including AM678=JWH018 found in 'Spice', examined using drug (Delta9-tetrahydrocannabinol) discrimination for rats. Behav Pharmacol. 2011; 22:498-507. [PubMed: 21836461]

20. Wu HM, Yang YM, Kim SG. Rimonabant, a CB1 Inverse Agonist, Inhibits Hepatocyte Lipogenesis by Activating LKB1 and AMPK Axis Downstream of G\{alpha $\}$ i/o Inhibition. Mol Pharmacol. 2011

21. Lindborg KA, Teachey MK, Jacob S, Henriksen EJ. Effects of in vitro antagonism of endocannabinoid-1 receptors on the glucose transport system in normal and insulin-resistant rat skeletal muscle. Diabetes Obes Metab. 2010; 12:722-30. [PubMed: 20590750]

22. Di Marzo V, Piscitelli F. Gut feelings about the endocannabinoid system. Neurogastroenterol Motil. 2011; 23:391-8. [PubMed: 21481098]

23. Rossi F, Bellini G, Luongo L, Torella M, Mancusi S, De Petrocellis L, et al. The endovanilloid/ endocannabinoid system: a new potential target for osteoporosis therapy. Bone. $2011 ; 48: 997-$ 1007. [PubMed: 21237298]

24. Bari M, Battista N, Pirazzi V, Maccarrone M. The manifold actions of endocannabinoids on female and male reproductive events. Front Biosci. 2011; 16:498-516. [PubMed: 21196184]

25. Dresen S, Ferreiros N, Putz M, Westphal F, Zimmermann R, Auwarter V. Monitoring of herbal mixtures potentially containing synthetic cannabinoids as psychoactive compounds. J Mass Spectrom. 2010; 45:1186-94. [PubMed: 20857386]

26. Sobolevsky T, Prasolov I, Rodchenkov G. Detection of JWH-018 metabolites in smoking mixture post-administration urine. Forensic Sci Int. 2010; 200:141-7. [PubMed: 20430547] 
27. Chimalakonda KC, Moran CL, Kennedy PD, Endres GW, Uzieblo A, Dobrowolski PJ, et al. SolidPhase Extraction and Quantitative Measurement of Omega and Omega-1 Metabolites of JWH-018 and JWH-073 in Human Urine. Anal Chem. 2011

28. Moran CL, Le VH, Chimalakonda KC, Smedley AL, Lackey FD, Owen SN, et al. Quantitative measurement of JWH-018 and JWH-073 metabolites excreted in human urine. Anal Chem. 2011; 83:4228-36. [PubMed: 21506519]

29. Uchiyama N, Kikura-Hanajiri R, Ogata J, Goda Y. Chemical analysis of synthetic cannabinoids as designer drugs in herbal products. Forensic Sci Int. 2010; 198:31-8. [PubMed: 20117892]

30. Penn HJ, Langman LJ, Unold D, Shields J, Nichols JH. Detection of synthetic cannabinoids in herbal incense products. Clin Biochem. 2011; 44:1163-5. [PubMed: 21741374]

31. Huffman JW, Dai D, Martin BR, Compton DR. Design, Synthesis, and Pharmacology of Cannabimimetic Indoles. Bioorg Med Chem Lett. 1994; 4:563-66.

32. Drugs-Forum. JWH-018 or JWH-073, which do you prefer?. Substance Information Network (S.I.N.) Foundation; 2009. <http://www.drugs-forum.com/forum/showthread.php?t=103276>

33. Moller I, Wintermeyer A, Bender K, Jubner M, Thomas A, Krug O, et al. Screening for the synthetic cannabinoid JWH-018 and its major metabolites in human doping controls. Drug Test Anal. 2010

34. Grigoryev A, Savchuk S, Melnik A, Moskaleva N, Dzhurko J, Ershov M, et al. Chromatographymass spectrometry studies on the metabolism of synthetic cannabinoids JWH-018 and JWH-073, psychoactive components of smoking mixtures. J Chromatogr B Analyt Technol Biomed Life Sci. 2011; 879:1126-36.

35. Brents LK, Reichard EE, Zimmerman SM, Moran JH, Fantegrossi WE, Prather PL. Phase I Hydroxylated Metabolites of the K2 Synthetic Cannabinoid JWH-018 Retain In Vitro and In Vivo Cannabinoid 1 Receptor Affinity and Activity. PLoS One. 2011; 6:e21917. [PubMed: 21755008]

36. Huffman JW, Zengin G, Wu MJ, Lu J, Hynd G, Bushell K, et al. Structure-activity relationships for 1-alkyl-3-(1-naphthoyl)indoles at the cannabinoid $\mathrm{CB}(1)$ and $\mathrm{CB}(2)$ receptors: steric and electronic effects of naphthoyl substituents. New highly selective $\mathrm{CB}(2)$ receptor agonists. Bioorg Med Chem. 2005; 13:89-112. [PubMed: 15582455]

37. Qi T, Qiu W, Liu Y, Zhang H, Gao X, Liu Y, et al. Synthesis, structures, and properties of disubstituted heteroacenes on one side containing both pyrrole and thiophene rings. J Org Chem. 2008; 73:4638-43. [PubMed: 18494524]

38. Denton JR. One-Pot Desultonylative Alkylation of N-Sulfonyl Azacycles Using Alkoxides Generated by Phase-Transfer Catalysis. Synthesis. 2010; 5:775-82.

39. Prather PL, Martin NA, Breivogel CS, Childers SR. Activation of cannabinoid receptors in rat brain by WIN 55212-2 produces coupling to multiple G protein alpha-subunits with different potencies. Mol Pharmacol. 2000; 57:1000-10. [PubMed: 10779385]

40. Shoemaker JL, Joseph BK, Ruckle MB, Mayeux PR, Prather PL. The endocannabinoid noladin ether acts as a full agonist at human CB2 cannabinoid receptors. J Pharmacol Exp Ther. 2005; 314:868-75. [PubMed: 15901805]

41. Cheng Y, Prusoff WH. Relationship between the inhibition constant (K1) and the concentration of inhibitor which causes 50 per cent inhibition (I50) of an enzymatic reaction. Biochem Pharmacol. 1973; 22:3099-108. [PubMed: 4202581]

42. Cheng HC. The power issue: determination of KB or Ki from IC50. A closer look at the ChengPrusoff equation, the Schild plot and related power equations. J Pharmacol Toxicol Methods. 2001; 46:61-71. [PubMed: 12481843]

43. Thomas A, Stevenson LA, Wease KN, Price MR, Baillie G, Ross RA, et al. Evidence that the plant cannabinoid Delta9-tetrahydrocannabivarin is a cannabinoid CB1 and CB2 receptor antagonist. $\mathrm{Br}$ J Pharmacol. 2005; 146:917-26. [PubMed: 16205722]

44. Aung MM, Griffin G, Huffman JW, Wu M, Keel C, Yang B, et al. Influence of the N-1 alkyl chain length of cannabimimetic indoles upon $\mathrm{CB}(1)$ and $\mathrm{CB}(2)$ receptor binding. Drug Alcohol Depend. 2000; 60:133-40. [PubMed: 10940540]

45. Smith PB, Compton DR, Welch SP, Razdan RK, Mechoulam R, Martin BR. The pharmacological activity of anandamide, a putative endogenous cannabinoid, in mice. J Pharmacol Exp Ther. 1994; 270:219-27. [PubMed: 8035318] 
46. Huestis MA. Human cannabinoid pharmacokinetics. Chem Biodivers. 2007; 4:1770-804. [PubMed: 17712819]

47. Atwood BK, Lee D, Straiker A, Widlanski TS, Mackie K. CP47,497-C8 and JWH073, commonly found in 'Spice' herbal blends, are potent and efficacious $\mathrm{CB}(1)$ cannabinoid receptor agonists. Eur J Pharmacol. 2011; 659:139-45. [PubMed: 21333643]

48. Mikasova L, Groc L, Choquet D, Manzoni OJ. Altered surface trafficking of presynaptic cannabinoid type 1 receptor in and out synaptic terminals parallels receptor desensitization. Proc Natl Acad Sci U S A. 2008; 105:18596-601. [PubMed: 19015531]

49. Burston JJ, Wiley JL, Craig AA, Selley DE, Sim-Selley LJ. Regional enhancement of cannabinoid $\mathrm{CB}_{1}$ receptor desensitization in female adolescent rats following repeated Deltatetrahydrocannabinol exposure. Br J Pharmacol. 2010; 161:103-12. [PubMed: 20718743]

50. Gorzalka BB, Hill MN. Putative role of endocannabinoid signaling in the etiology of depression and actions of antidepressants. Prog Neuropsychopharmacol Biol Psychiatry. 2010

51. Li C, Jones PM, Persaud SJ. Role of the endocannabinoid system in food intake, energy homeostasis and regulation of the endocrine pancreas. Pharmacol Ther. 2011; 129:307-20. [PubMed: 21055418]

52. Watkins BA, Hutchins H, Li Y, Seifert MF. The endocannabinoid signaling system: a marriage of PUFA and musculoskeletal health. J Nutr Biochem. 2010; 21:1141-52. [PubMed: 20934863]

53. Karst M, Wippermann S, Ahrens J. Role of cannabinoids in the treatment of pain and (painful) spasticity. Drugs. 2010; 70:2409-38. [PubMed: 21142261]

54. Bisogno T, Di Marzo V. Cannabinoid receptors and endocannabinoids: role in neuroinflammatory and neurodegenerative disorders. CNS Neurol Disord Drug Targets. 2010; 9:564-73. [PubMed: 20632970]

55. Gorzalka BB, Hill MN, Chang SC. Male-female differences in the effects of cannabinoids on sexual behavior and gonadal hormone function. Horm Behav. 2010; 58:91-9. [PubMed: 19733173]

56. Jutras-Aswad D, DiNieri JA, Harkany T, Hurd YL. Neurobiological consequences of maternal cannabis on human fetal development and its neuropsychiatric outcome. Eur Arch Psychiatry Clin Neurosci. 2009; 259:395-412. [PubMed: 19568685]

57. McKallip RJ, Nagarkatti M, Nagarkatti PS. Delta-9-tetrahydrocannabinol enhances breast cancer growth and metastasis by suppression of the antitumor immune response. J Immunol. 2005; 174:3281-9. [PubMed: 15749859]

58. Haney M. The marijuana withdrawal syndrome: diagnosis and treatment. Curr Psychiatry Rep. 2005; 7:360-6. [PubMed: 16216154]

59. Allsop DJ, Norberg MM, Copeland J, Fu S, Budney AJ. The Cannabis Withdrawal Scale development: Patterns and predictors of cannabis withdrawal and distress. Drug Alcohol Depend. 2011

60. Hirvonen J, Goodwin RS, Li CT, Terry GE, Zoghbi SS, Morse C, et al. Reversible and regionally selective downregulation of brain cannabinoid $\mathrm{CB}(1)$ receptors in chronic daily cannabis smokers. Mol Psychiatry. 2011

61. Budney AJ, Hughes JR. The cannabis withdrawal syndrome. Curr Opin Psychiatry. 2006; 19:2338. [PubMed: 16612207]

62. Vandrey R, Umbricht A, Strain EC. Increased blood pressure after abrupt cessation of daily cannabis use. J Addict Med. 2011; 5:16-20. [PubMed: 21359104]

63. Drugs-Forum. JWH-073 experiences. Substance Information Network (S.I.N.) Foundation; 2009. <http://www.drugs-forum.com/forum/showthread.php?t=82829>

64. Di Marzo V, Matias I. Endocannabinoid control of food intake and energy balance. Nat Neurosci. 2005; 8:585-9. [PubMed: 15856067]

65. Beyer CE, Dwyer JM, Piesla MJ, Platt BJ, Shen R, Rahman Z, et al. Depression-like phenotype following chronic CB1 receptor antagonism. Neurobiol Dis. 2010; 39:148-55. [PubMed: 20381618]

66. Moreira FA, Grieb M, Lutz B. Central side-effects of therapies based on CB1 cannabinoid receptor agonists and antagonists: focus on anxiety and depression. Best Pract Res Clin Endocrinol Metab. 2009; 23:133-44. [PubMed: 19285266] 
67. Bergman J, Delatte MS, Paronis CA, Vemuri K, Thakur GA, Makriyannis A. Some effects of CB1 antagonists with inverse agonist and neutral biochemical properties. Physiol Behav. 2008; 93:66670. [PubMed: 18076956]

68. Pertwee RG. Pharmacological actions of cannabinoids. Handb Exp Pharmacol. 2005:1-51. [PubMed: 16596770]

69. Cluny NL, Chambers AP, Vemuri VK, Wood JT, Eller LK, Freni C, et al. The neutral cannabinoid CB receptor antagonist AM4113 regulates body weight through changes in energy intake in the rat. Pharmacol Biochem Behav. 2010; 97:537-43. [PubMed: 21056053]

70. Sink KS, Segovia KN, Collins LE, Markus EJ, Vemuri VK, Makriyannis A, et al. The CB1 inverse agonist AM251, but not the CB1 antagonist AM4113, enhances retention of contextual fear conditioning in rats. Pharmacol Biochem Behav. 2010; 95:479-84. [PubMed: 20347865]

71. Kunos G, Osei-Hyiaman D, Batkai S, Sharkey KA, Makriyannis A. Should peripheral CB(1) cannabinoid receptors be selectively targeted for therapeutic gain? Trends in pharmacological sciences. 2009; 30:1-7. [PubMed: 19042036]

72. Tam J, Vemuri VK, Liu J, Batkai S, Mukhopadhyay B, Godlewski G, et al. Peripheral CB1 cannabinoid receptor blockade improves cardiometabolic risk in mouse models of obesity. J Clin Invest. 2010; 120:2953-66. [PubMed: 20664173] 
A
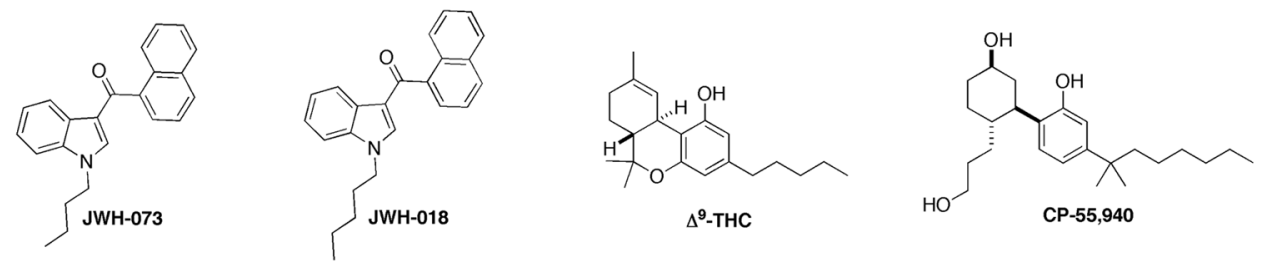

B

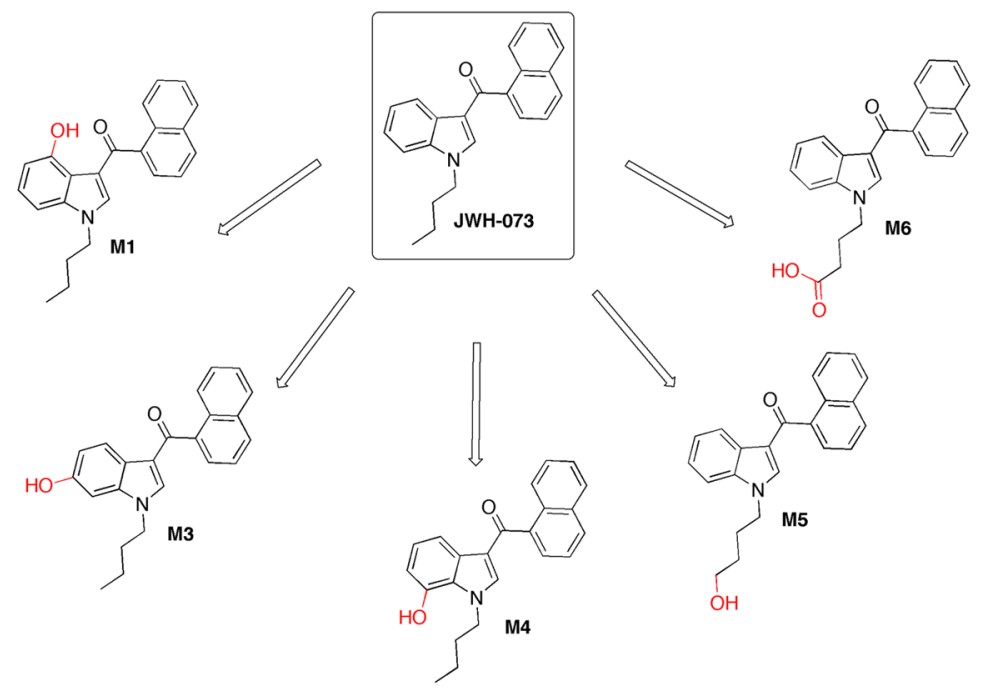

Figure 1. Cannabinoids examined in the present study

A. Structures of significant cannabinoids discussed and utilized in the present work. B. Structures of JWH-073 [(1-butyl-1H-indole-3-yl)-1-naphthalenyl-methanone] and its potential metabolites, here designated M1 [(1-butyl-4-hydroxy-1H-indole-3-yl)

(naphthalen-1-yl-methanone], M3 [(1-butyl-6-hydroxy-1H-indole-3-yl)(naphthalen-1-ylmethanone], M4 [(1-butyl-7-hydroxy-1H-indole-3-yl)(naphthalen-1-yl-methanone], M5 [1(4-hydroxybutyl-1H-indole-3-yl)(naphthalen-1-yl)-methanone] and M6 ([4-(3-(1naphthoyl)-1H-indole-1-yl)-1-butanoic acid]), examined for CB1R affinity and activity. 

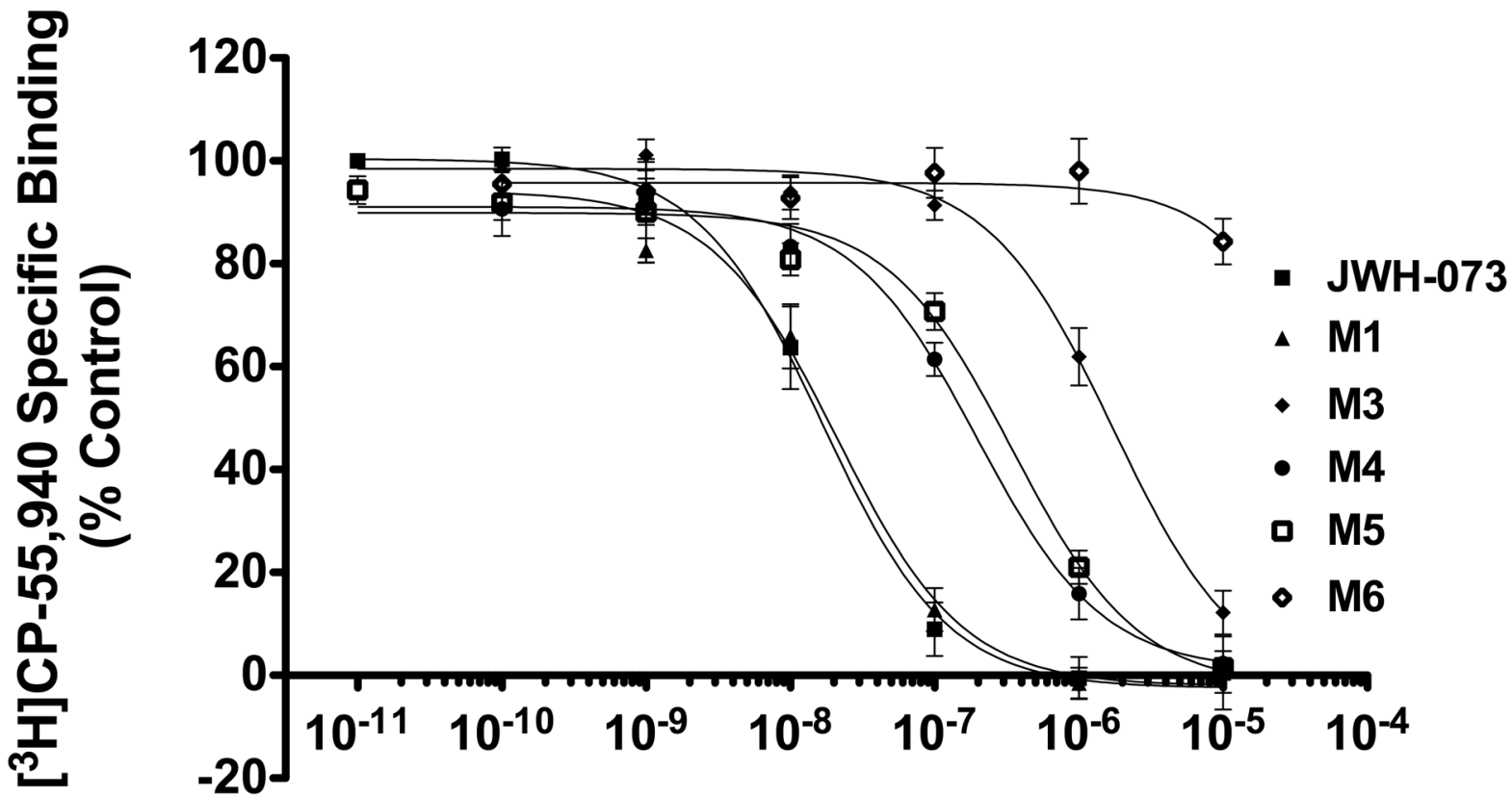

[Drug, M]

Figure 2. JWH-073, M1, M3, M4, M5, but not M6, bind to CB1R receptors In competition receptor binding assays, JWH-073, M1, M3, M4, and M5 completely displaced $\left[{ }^{3} \mathrm{H}\right] \mathrm{CP}-55,940$ from CB1Rs in mouse brain homogenates with nanomolar (JWH-073, M1, M4, M5) to micromolar (M3) affinity, while M6 displaced less than 10\% $\left[{ }^{3} \mathrm{H}\right] \mathrm{CP}-55,940$ specific binding, signifying M6 has little or no CB1R affinity $(n=3-6)$. 


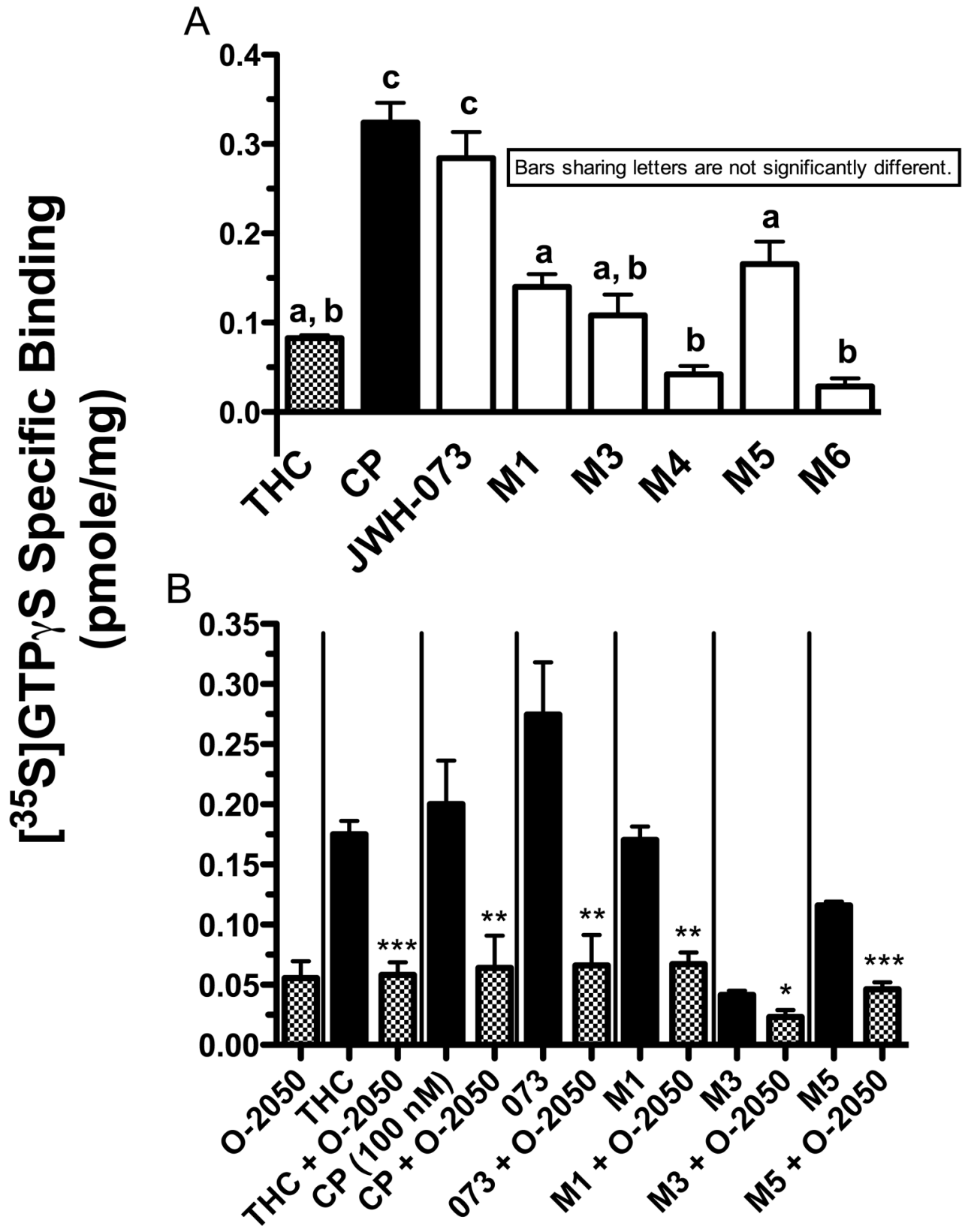

Figure 3. JWH-073, M1, M3 and M5, but not M4, activate CB1Rs in mouse brain homogenates A. A receptor-saturating concentration $(10 \mu \mathrm{M})$ of JWH-073 in the $\left[{ }^{35} \mathrm{~S}\right] \mathrm{GTP} \gamma \mathrm{S}$ binding assay activated G-proteins in mouse brain homogenates with full agonist activity equivalent to that produced by CP-55,940. M1, M3 and M5, but not M4 or M6, activate G-proteins with efficacy equivalent to that produced by $\Delta^{9}$-THC. Values designated by different letters are significantly different $(P<0.05$, one way ANOVA with Tukey's Multiple Comparison post-hoc test, mean \pm SEM, $\mathrm{n}=3-8$ ). B. Activation of $\mathrm{G}$-proteins in mouse brain homogenates by JWH-073, M1, M3, and M5 (1 $\mu \mathrm{M}$, solid bars) was significantly attenuated by co-incubation with the CB1R-selective antagonist O-2050 $(1 \mu \mathrm{M}$, checkered bars), signifying that JWH-073, M1, M3 and M5 activate G-proteins via CB1Rs. $(* P<0.05$, $* * P<0.01, * * * P<0.001$ vs. cannabinoid alone, Student's t-test, mean $\pm \mathrm{SEM}, \mathrm{n}=3-6)$ Note: 
Because of its higher CB1R affinity, $100 \mathrm{nM}$, instead of $1 \mu \mathrm{M}$, of CP-55,940 was used in the CB1R blockade assay. 


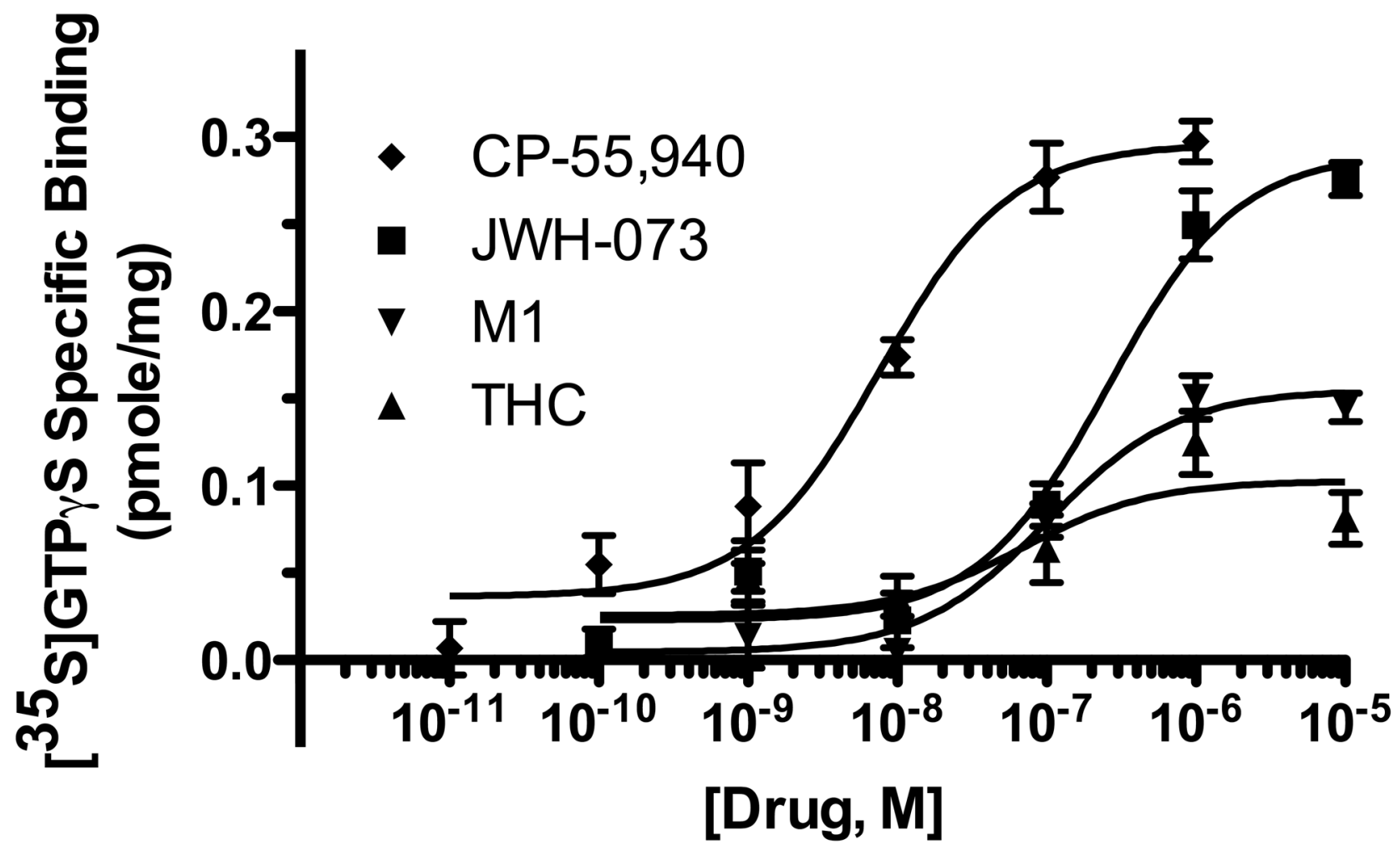

Figure 4. G-protein activation by JWH-073 and M1 via CB1Rs is concentration-dependent The potency and maximal efficacy of CP-55,940, JWH-073, M1, and $\Delta^{9}$-THC to activate CB1Rs in mouse brain homogenates were determined employing the $\left[{ }^{35} \mathrm{~S}\right] \mathrm{GTP} \gamma \mathrm{S}$ binding assay (mean \pm SEM, $n=3-4$ ). 


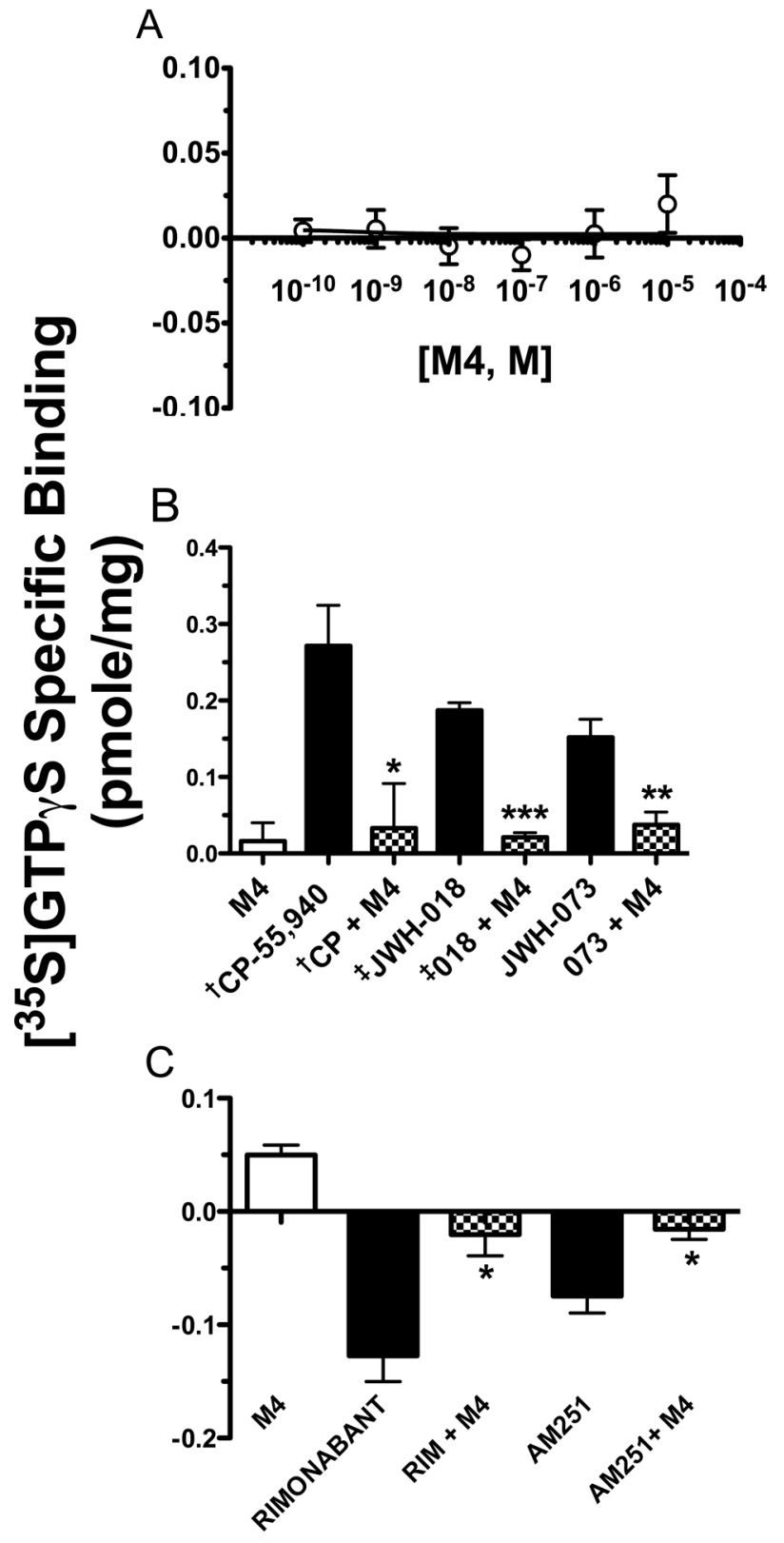

Figure 5. M4 antagonizes the actions of both CB1R agonists and inverse agonists in mouse brain homogenates, while having no activity when tested alone

A. In the $\left[{ }^{35} \mathrm{~S}\right] \mathrm{GTP} \gamma \mathrm{S}$ binding assay, M4 when examined alone, up to $10 \mu \mathrm{M}$ concentrations, showed neither agonist nor inverse agonist activity in mouse brain homogenates. B. M4 (10 uM) blocked the activity produced by CB1R agonists (100 nM CP, $1 \mu \mathrm{M}$ JWH-018, and $500 \mathrm{nM}$ JWH-073) and C. inverse agonists (10 $\mu \mathrm{M}$ Rimonabant and AM251) $(* P<0.05, * * P<0.01, * * * P<0.001$ vs. cannabinoid alone, Student's t-test, mean \pm SEM, $n=3-6 ; \dagger, \ddagger$ These data are of the same data presented in figures $6 \mathrm{~A}[\dagger]$ and $6 \mathrm{~B}[\ddagger]$.) 


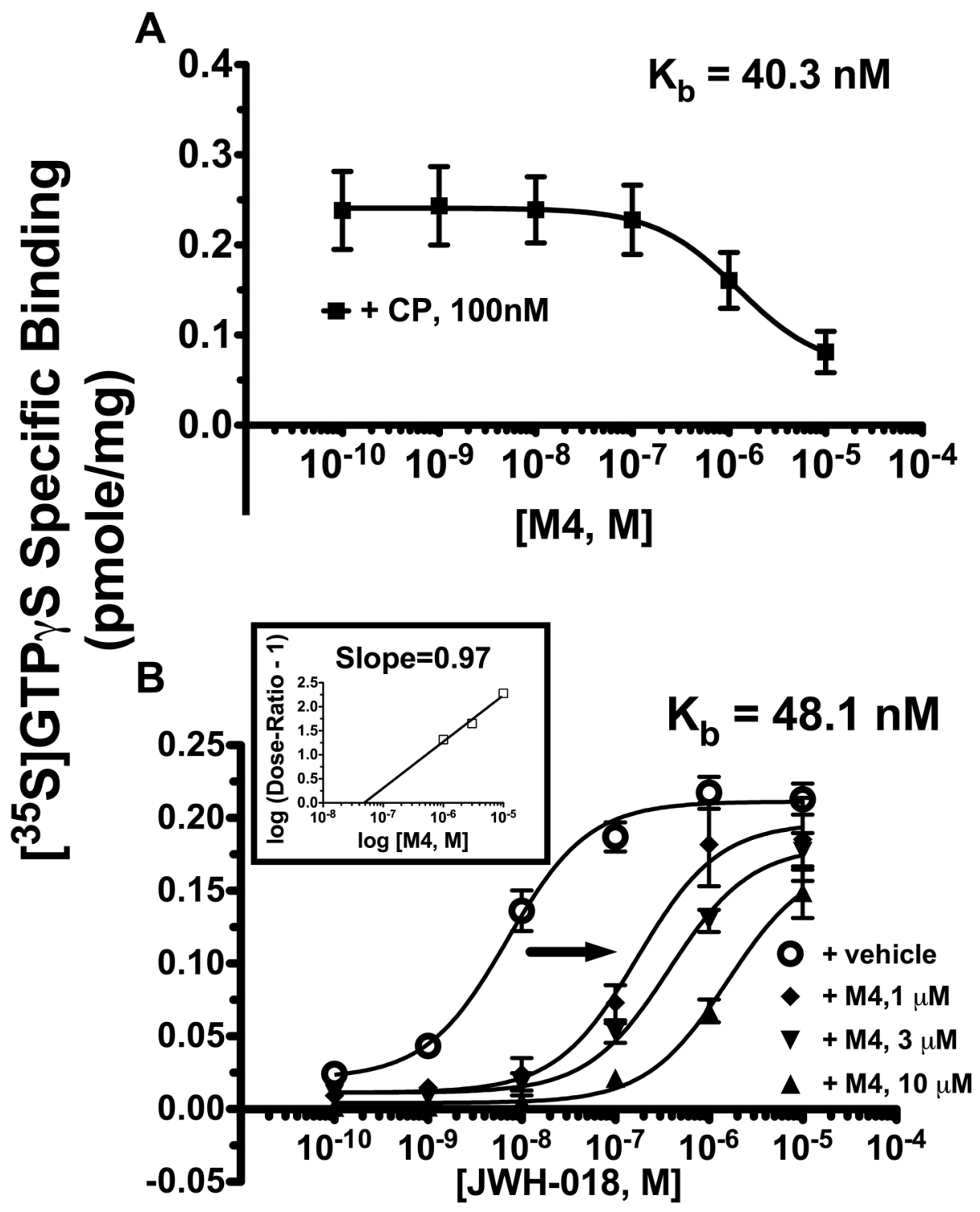

Figure 6. M4 acts as an in vitro competitive neutral antagonist at CB1Rs A. M4 blocks CB1R activation of G-proteins produced by an $\mathrm{EC}_{90}$ concentration of CP-55,940 in mouse brain homogenates with a nanomolar $\mathrm{K}_{\mathrm{b}}$. B. Schild analysis of the concentration-dependent antagonism of JWH-018 by M4 yielded a nanomolar $\mathrm{K}_{\mathrm{b}}$ and a slope (not significantly different that 1 ) that indicates a competitive mechanism of antagonism (inset). The arrow indicates significant rightward-shifts in the potency of Gprotein activation produced by JWH-018 in response to co-administration with increasing concentrations of M4. 

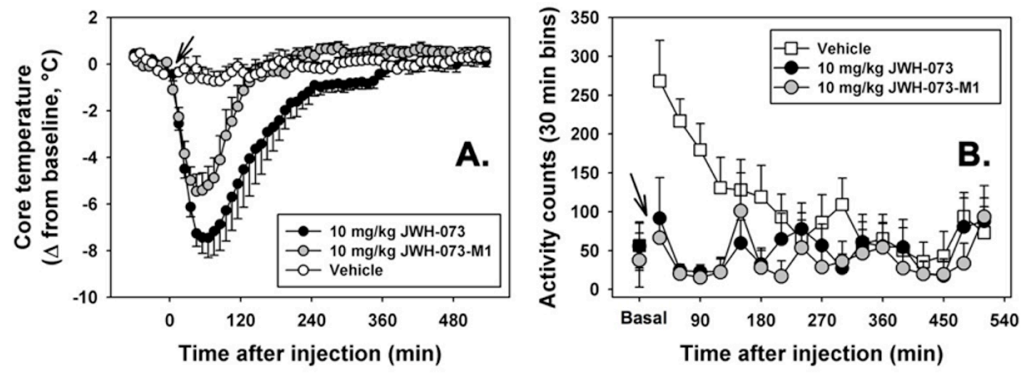

Figure 7. M1 induces hypothermia and locomotor suppression similar to JWH-073

Time course telemetry data shows that both JWH-073 (10 mg/kg, i.p., black circles) and M1 (10 mg/kg, i.p. gray circles) produce A. robust hypothermia, and B. locomotor suppression, relative to vehicle control. This indicates that M1 retains the partial-to-full potency and efficacy of JWH-073 to produce hypothermia and locomotor suppression. Arrow indicates time of vehicle or cannabinoid administration. 

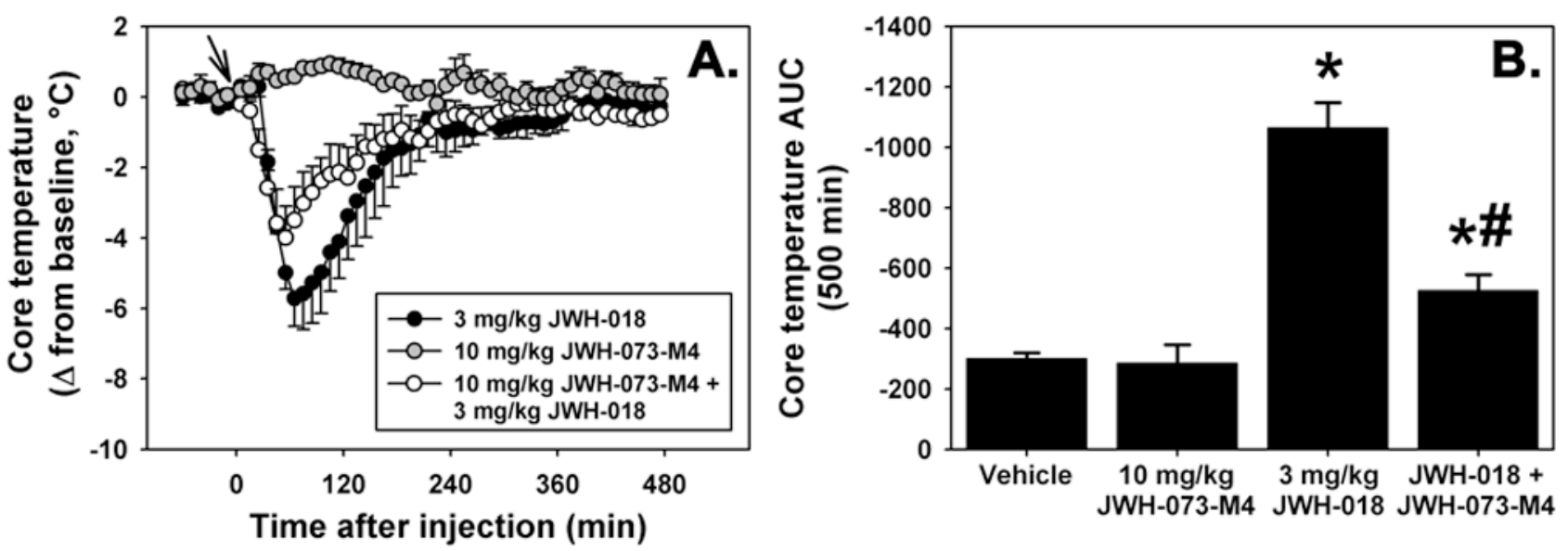

Figure 8. M4 blunts JWH-018 induced hypothermia in mice

A. Time course telemetry data after administration of JWH-018 (3 mg/kg, i.p., black circles), M4 (10 mg/kg, i.p., gray circles), or co-administration of these doses (white circles). Arrow indicates time of vehicle or cannabinoid administration. B. Area under the curve summation of telemetry data collected 0-500 minutes after vehicle or cannabinoid administration shows that M4 significantly attenuated hypothermia induced by JWH-018, indicating that M4 displays CB1R antagonism in vivo. $(* \mathrm{P}<0.05$ vs. vehicle, \#P<0.05 vs. JWH-018 alone, one-way ANOVA with Tukey HSD test, mean \pm SEM, $n=5$ ). 

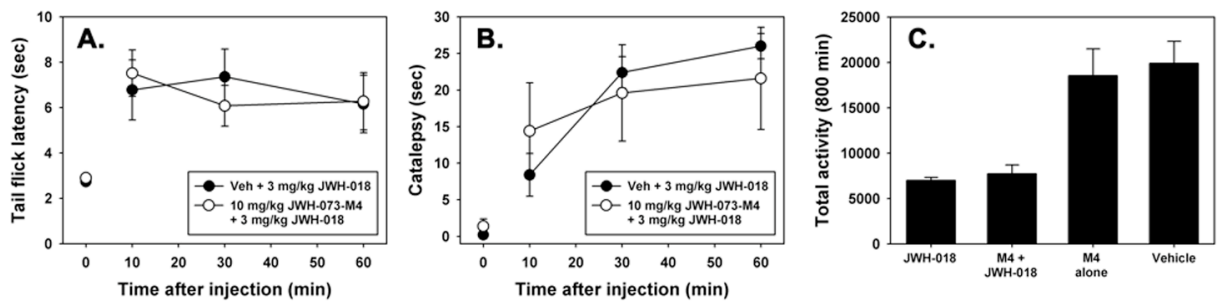

Figure 9. M4 does not antagonize analgesia, catalepsy or locomotor suppression induced by JWH-018

Administration of JWH-018 (3 mg/kg, i.p., black circles) produces A. robust analgesia (tail flick assay), B. catalepsy, and C. locomotor suppression. Co-administration of M4 (10 mg/ $\mathrm{kg}$, i.p., white circles) does not significantly alter any of the JWH-018-induced effects $(\mathrm{P}<0.05$, one-way ANOVA with Tukey HSD test, mean \pm SEM, $n=5-6)$. 


\section{Table 1}

Comparison of CB1R affinity with potency and efficacy for G-protein activation produced by cannabinoid ligands

\begin{tabular}{llll}
\hline & {$\left[{ }^{3} \mathbf{H}\right] \mathbf{C P}$ binding } & \multicolumn{2}{c}{$\left[{ }^{35} \mathbf{S}\right] \mathbf{G T P} \gamma \mathbf{S}$ Binding } \\
\hline Drug & $\mathbf{K}_{\mathbf{i}}(\mathbf{n M})$ & $\mathbf{E C}_{\mathbf{5 0}}(\mathbf{n M})$ & $\mathbf{E}_{\mathbf{m a x}}(\mathbf{p m o l e} / \mathbf{m g})$ \\
\hline CP-55,940 & $0.26 \pm 0.1^{\dagger}$ & $7.5 \pm 1.8$ & $0.26 \pm 0.01^{a}$ \\
\hline JWH-073 & $12.9 \pm 3.4$ & $276.5 \pm 65.3$ & $0.27 \pm 0.01^{a}$ \\
\hline M1 & $14.1 \pm 3.5$ & $112.9 \pm 29.2$ & $0.14 \pm 0.01^{b}$ \\
\hline$\Delta^{9}$-THC & $15.3 \pm 4.5^{\dagger}$ & $77.0 \pm 29.9$ & $0.08 \pm 0.01^{c}$ \\
\hline${ }^{\dagger}$ Values previously reported [35] & & \\
a,b,c Values designated by different letters are significantly different.
\end{tabular}

$P<0.05$, one-way ANOVA, Tukey Post-hoc test; Reported as mean \pm SEM, $\mathrm{n}=3-4$ 
Table 2

G-protein activation by JWH-073 and metabolites, and blockade by the selective CB1R antagonist O-2050

\begin{tabular}{lllll}
\hline Drug & \multicolumn{4}{c}{${ }^{35}$ S $]$ GTP $\gamma$ S Binding (pmole/mg) } \\
\cline { 2 - 5 } & $\mathbf{1 0} \mu \mathbf{M}$ & $\mathbf{1} \boldsymbol{\mu M}$ & $\mathbf{1 0 0} \mathbf{~ M}$ & $+\mathbf{O - 2 0 5 0}(\mathbf{1} \boldsymbol{\mu M})^{\dagger}$ \\
\hline$\Delta^{9}$-THC & $0.08 \pm 0.00^{a}, b$ & $0.17 \pm 0.01$ & $\mathrm{ND}$ & $0.06 \pm 0.01^{* * *}$ \\
\hline${\mathrm{CP}-55,940^{\dagger \dagger}}^{*}$ & $0.32 \pm 0.02^{c}$, & $\mathrm{ND}$ & $0.20 \pm 0.04$ & $0.06 \pm 0.03^{* *}$ \\
\hline JWH-073 & $0.28 \pm 0.03^{c}$ & $0.27 \pm 0.04$ & $\mathrm{ND}$ & $0.07 \pm 0.02^{* *}$ \\
\hline M1 & $0.14 \pm 0.01^{a}$ & $0.17 \pm 0.01$ & $\mathrm{ND}$ & $0.07 \pm 0.01^{* *}$ \\
\hline M3 & $0.11 \pm 0.02^{a}, b$ & $0.04 \pm 0.00$ & $\mathrm{ND}$ & $0.02 \pm 0.01^{*}$ \\
\hline M4 & $0.04 \pm 0.01^{b}$ & $\mathrm{ND}$ & $\mathrm{ND}$ & $\mathrm{ND}$ \\
\hline M5 & $0.16 \pm 0.02^{a}$ & $0.12 \pm 0.00$ & $\mathrm{ND}$ & $0.05 \pm 0.01^{* * *}$ \\
\hline M6 & $0.03 \pm 0.01^{b}$ & $\mathrm{ND}$ & $\mathrm{ND}$ & $\mathrm{ND}$ \\
\hline
\end{tabular}

${ }^{a, b, c}$ Values designated by different letters are significantly different.

$P<0.05$, one-way ANOVA with Tukey's post-hoc test, reported as mean $\pm \mathrm{SEM}, \mathrm{n}=3-8$;

${ }^{\dagger} \mathrm{E}_{\max }$ of $\mathrm{O}-2050$ alone $(1 \mu \mathrm{M})=0.05 \pm 0.01$

${ }^{\dagger}$ Due to its high affinity, $100 \mathrm{nM}$ of CP-55,940 was used instead of $1 \mu \mathrm{M}$;

* $\mathrm{P}<0.05$;

** $\mathrm{P}<0.01$

***

$\mathrm{P}<0.001$, vs. drug alone, Student's $t$-test, reported as mean $\pm \mathrm{SEM}, \mathrm{n}=3-9$.

ND, Not Determined 